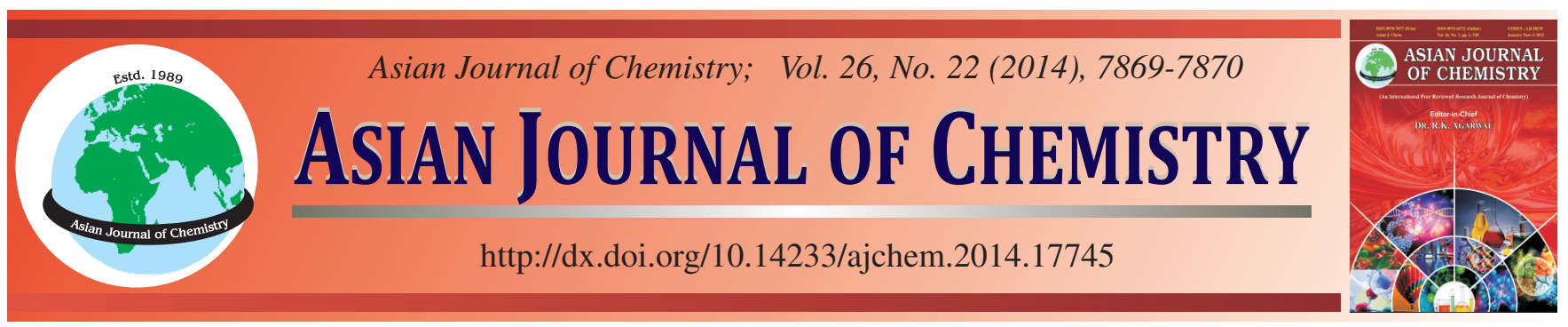

NOTE

\title{
Simultaneous Determination of Iodide, Sulphate, Fluoride and Nitrite in Salt Samples by Ion Chromatography
}

\author{
XIA Ning* and Ji-HuA ZHANG
}

Zhangqiu Centers for Disease Control and Prevention of Province, Zhangqiu 250200, Shandong Province, P.R. China

*Corresponding author: E-mail: sdzqnx@163.com

\begin{abstract}
Simultaneous determination of iodide, sulphate, fluoride and nitrite in salt samples by ion chromatography was demonstrated in this paper. To avoid the interference of $\mathrm{Cl}^{-}$, solid $\mathrm{Ag}_{2} \mathrm{O}$ was used as a precipitator. After that, ascorbic acid was added to reduce the iodate to iodide ion. In the analysis process, IonPac.RAS19 $4 \times 250 \mathrm{~mm}$ was selected with IonPacAG19 $4 \times 50 \mathrm{~mm}$ as guard column. Leachate of potassium oxide solution was used with $1 \mathrm{~mL} / \mathrm{min}$ flow velocity. Linearity ranges of iodide, sulphate, fluoride and nitrite were $0.1-10$, $0.05-1,0.01-0.80$ and $0.01-0.80 \mu \mathrm{g} / \mathrm{mL}$, respectively and high correlations $\left(\mathrm{R}^{2}\right)$ were all above 0.999 . Limits of detection (LOD) were 10 $\mathrm{mg} / \mathrm{kg}$ (iodide ion), $5 \mathrm{mg} / \mathrm{kg}$ (sulphate), $1 \mathrm{mg} / \mathrm{kg}$ (fluoride) and $1 \mathrm{mg} / \mathrm{kg}$ (nitrite). This method is simple and convenient with rapid, accurate and high sensitivity which could be accepted in daily analysis.
\end{abstract}

Keywords: Ion chromatography, Table salt, Iodide, Fluoride, Sulphate, Nitrite.

Iodine is usually added in salt to prevention the iodine deficiency disease worldwide. Therefore, the treated salt was called iodide salt. Low or high inputs of iodine could both bring the negative impacts on human health ${ }^{1}$. The sulphate, fluoride and nitrite in salt samples were generally regarded as impurities. Higher concentrations of them indicate lower salt purity. In analysis of iodine, more attention should be paid to the influence of large amount of chloride ion, which could cause heavy disturbance ${ }^{2}$. At present, silver-column method is always used to remove chloride ion in other negative ion determination with ion chromatography methods for its highest efficiency ${ }^{3,4}$. But it is expensive for large amount of silver would be used in the process of high levels of chloride ion solution passing through the high capacity $\mathrm{Ag}^{+}$-exchange column. So the silver-column method is not widely accepted for expensive cost. Then the solid $\mathrm{Ag}_{2} \mathrm{O}$ was selected to remove chloride ion in this study. Now, the determination methods of iodine in salt sample are mainly focus on volumetric method, catalytic dynamics method and gas chromatographic method ${ }^{5-8}$. In addition, spectrophotometric method has been used to analysis of sulphate, fluoride and nitrite ${ }^{9-11}$, while the process is termwise with large workload for a long period and even the data results are always influenced by the experimental conditions and manual operation. Electrical conductivity detector of ion chromatography could simultaneously determination of iodide, sulphate, fluoride and nitrite in salt samples. This method is simple operation, rapid, accurate and could meet requirements in daily analysis.

ICS-2000 instrument equipped with automatically generator of eluent was used in the experiment. Water was purified using a Milli-Q system (Millipore, Bedford, MA, USA) and used to confect all standard solutions. Standard solutions of potassium iodate, sulphate, fluoride and nitrite were all purchased from National Research Center for Certified Reference Material (NRCCRMS) of China.

Anion analytical column (Dionex IonPac AS19, $4 \times 250$ $\mathrm{mm}$ ), guard column (Dionex IonPac AG19, $4 \times 50 \mathrm{~mm}$ ), suppressor (ASRS $4 \mathrm{~mm}$ ), electrical conductivity detector, leaching with $30 \mathrm{mmol} / \mathrm{L} \mathrm{KOH}$ at a flow rate of $1 \mathrm{~mL} / \mathrm{min}$, suppression current was $75 \mathrm{~mA}$ and injection volume was $25 \mu \mathrm{L}$, the column temperature was $30^{\circ} \mathrm{C}$.

Sample pretreatment: About $1 \mathrm{~g}$ salt sample and $0.10 \mathrm{~g}$ ascorbic acid were weighted and mixed in volumetric flask. After dissolution, about $15 \mathrm{~mL}$ solution were taken out and injected in $20 \mathrm{~mL}$ centrifuge tube. After added $0.3 \mathrm{~g}$ $\mathrm{Ag}_{2} \mathrm{O}$, the black $\mathrm{Ag}_{2} \mathrm{O}$ turned into white $\mathrm{AgCl}$ precipitate with continuous agitation by glass rod. More $\mathrm{Ag}_{2} \mathrm{O}$ was added up to the black precipitate occurred, which indicated the excessive $\mathrm{Ag}_{2} \mathrm{O}$ existing in solution. Centrifuged for 2 min, $10 \mathrm{~mL}$ supernatant were taken out and put them pass through $0.22 \mu \mathrm{m}$ membrane filter. Leachate was used to determination. 
TABLE-1

PRECISION AND RECOVERY STUDIES $(n=6)$

\begin{tabular}{|c|c|c|c|c|}
\hline Parameters & Concentration $(\mu \mathrm{g} / \mathrm{mL})$ & Amount recovered $(\mu \mathrm{g} / \mathrm{mL})$ & Recovery (\%) & $\operatorname{RSD}(\%)$ \\
\hline \multirow{3}{*}{$\mathrm{I}^{-}$} & 0.20 & 0.21 & 105.0 & 3.25 \\
\hline & 3.00 & 3.09 & 103.0 & 2.30 \\
\hline & 5.00 & 4.99 & 99.8 & 1.07 \\
\hline \multirow{3}{*}{$\mathrm{SO}_{4}{ }^{2-}$} & 0.20 & 0.19 & 95.0 & 2.77 \\
\hline & 0.50 & 0.51 & 102.0 & 1.45 \\
\hline & 1.00 & 1.01 & 101.0 & 1.10 \\
\hline \multirow{3}{*}{$\mathrm{F}^{-}$} & 0.20 & 0.19 & 95.0 & 3.56 \\
\hline & 0.40 & 0.41 & 102.5 & 2.31 \\
\hline & 0.80 & 0.79 & 98.7 & 1.50 \\
\hline \multirow{3}{*}{$\mathrm{NO}_{2}^{-}$} & 0.20 & 0.21 & 105.0 & 3.03 \\
\hline & 0.40 & 0.39 & 97.5 & 2.46 \\
\hline & 0.80 & 0.83 & 103.7 & 1.79 \\
\hline
\end{tabular}

Reductant selection: Ion chromatography method to determination of iodine had been reported ${ }^{12}$ and always the iodine in salt was directly determined in those methods. But now, the salt sold in the market is always added with potassium iodate ${ }^{13}$, it is necessary to reduce the iodate to iodide for more accurate results. Various reducing agents, such as hydrazine hydrate, hydroquinone, sodium thiosulfate, sodium sulphide and ascorbic acid were tested in our experiments. Among them, neither hydrazine hydrate nor hydroquinone is suitable for the required reduction condition. The effects of thiosulfate, sodium sulphide and ascorbic acid behaved better. But considerate of the high affinity ability of thiosulfate to anion exchange column, which meant longer analysis time and lower working efficiency, the thiosulfate was not the first choice. Sodium sulphide, as another reducing agent, large amount of them would influence the detection of iodide anion ${ }^{14}$. Ascorbic acid had no above faults and was suitable to all the required conditions. In this paper, the effects of five levels of ascorbic acid $(0.1,0.5,1.0,5.0$ and $10 \%)$ were attempted. When the concentration of $0.1 \%$ was tested, the iodate could be turned into iodide completely. Therefore, this is the suitable concentration of ascorbic acid.

Added amount of $\mathrm{Ag}_{2} \mathrm{O}$ and stirring time: The colour of precipitate was used to control the amount of $\mathrm{Ag}_{2} \mathrm{O}$. When less $\mathrm{Ag}_{2} \mathrm{O}$ added, the black $\mathrm{Ag}_{2} \mathrm{O}$ would be turned into white $\mathrm{AgCl}$. With more $\mathrm{Ag}_{2} \mathrm{O}$ added, the colour of solution will become black, which indicated excessive $\mathrm{Ag}_{2} \mathrm{O}$ existing in solution. After stirring for $8 \mathrm{~min}$, the reducing velocity of $\mathrm{Cl}^{-}$was very slow. At this time, the $\mathrm{Cl}^{-}$could not influence the detection of other anions and no stirring needed any more. The time of 8 min was selected as stirring time.

Linear range and limit of detection: The linear ranges of iodide ion, sulphate, fluoride and nitrite in salt samples were $0.1-10.00,0.05-1.00,0.01-0.80$ and $0.01-0.80 \mu \mathrm{g} / \mathrm{mL}$, respectively. The calibration curves of the target substances showed good linearity with $\mathrm{R}^{2}>0.999$. The limit of detection was estimated at a $\mathrm{S} / \mathrm{N}$ of 3 and the results were $10 \mathrm{mg} / \mathrm{kg}$ (iodide ion), $5 \mathrm{mg} / \mathrm{kg}$ (sulphate), $1 \mathrm{mg} / \mathrm{kg}$ (fluoride) and $1 \mathrm{mg} / \mathrm{kg}$ (nitrite).

Degree of precision and accuracy: Standard solutions were added in the salt samples with known concentrations. With low, middle and high levels of standard solutions added and analyzed for 6 time, the RSD (relative standard deviation) could be calculated as $1.30-3.25 \%$ (iodide ion), 1.10-2.77 \% (sulphate), 1.50$3.56 \%$ (fluoride), $1.79-3.03 \%$ (nitrite). The recovery of them were 99.8-105, 95-102, 95-102.5 and 97.5-105\%, respectively. The results could be accepted (Table-1).

Effect of co-existing ion: As demonstrated in Fig. 1, after separated by ion separation column, the common anion like as $\mathrm{Cl}^{-}, \mathrm{NO}_{3}{ }^{-}, \mathrm{PO}_{4}{ }^{3-}$ could be separated completely and no interferance happened.

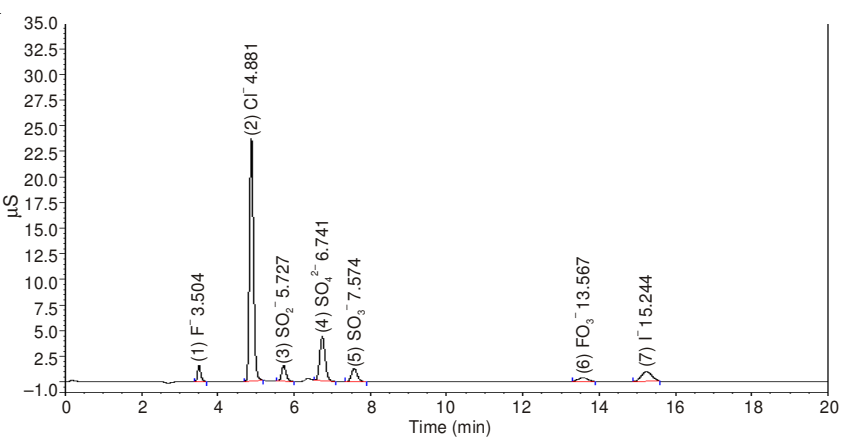

Fig. 1. Chromatogram of salt sample without chloride ion

The results of degree of precision indicated the method built in the experiment was suitable to simultaneously determination of iodide ion, sulphate, fluoride and nitrite in salt samples. Compared to other methods, this method has high sensitivity, good selectivity, simple operation, less disturbance and lower cost. It could be accepted in simultaneously determination of iodide, sulphate, fluoride and nitrite in salt samples in daily analysis.

\footnotetext{
REFERENCES

1. Y. Zhao and X.-Y. Lin, Chin. J. Publ. Health, 22, 492 (2006).

2. People's Republic of China National Standard, Hygienic Standard for Food Grade Salt, (GB 2721-2003).

3. P. Razpotnik, J. Turšic, M. Veber and M. Novic, J. Chromatogr. A, 991, 23 (2003).

4. L. Barron and B. Paull, Anal. Chim. Acta, 522, 153 (2004).

5. G.-R. Mo, Chin. J. Nat. Med., 4, 149 (2007).

6. H.-Q. Huang, Food Sci., 23, 122 (2002).

7. H.-T. Fu, Chinese J. Anal. Chem., 31, 376 (2003).

8. L. Zhu, Chinese J. Health Lab. Technol., 15, 1334 (2005).

9. S.-M. Mo and L.-N. Liang, Fenxi Ceshi Xuebao, 25, 105 (2006).

10. People's Republic of China National Standard, Physical Part of Food Hygiene Inspection (GB/T5009.42-2003).

11. People's Republic of China National Standard, Physical Part of Food Hygiene Inspection (GB/T5009.33-2010).

12. R.D. Rocklin and E.L. Johnson, Anal. Chem., 55, 4 (1983).

13. Y.-L. Yang and L. Lin, Chinese J. Anal. Chem., 38, 1381 (2010).

14. H.-T. Fu, L.-M. Fu and Y.-L. Zhang, Chinese J. Anal. Chem., 27, 684
} (1999). 